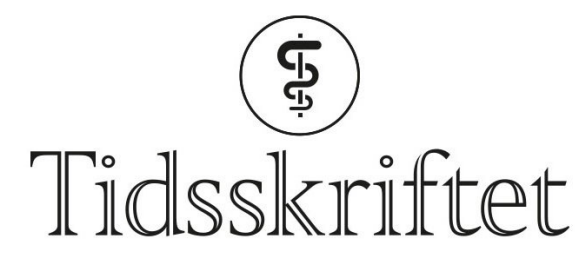

DEN NORSKE LEGEFORENING

\title{
Panners sykdom
}

MEDISINEN I BILDER

\section{HEGE NORDLIE}

E-post: hegeja@vestreviken.no

Bildediagnostisk avdeling

Bærum sykehus

Hege Nordlie er spesialist i radiologi.

Forfatteren har fylt ut ICMJE-skjemaet og oppgir ingen interessekonflikter.

\section{MAJA ROGNSTAD}

Ortopedisk avdeling

Bærum sykehus

Maja Rognstad er lege i spesialisering.

Forfatteren har fylt ut ICMJE-skjemaet og oppgir ingen interessekonflikter.

\section{HEGE IVELAND}

Bildediagnostisk avdeling

Drammen sykehus

Hege Iveland er spesialist i radiologi.

Forfatteren har fylt ut ICMJE-skjemaet og oppgir ingen interessekonflikter.

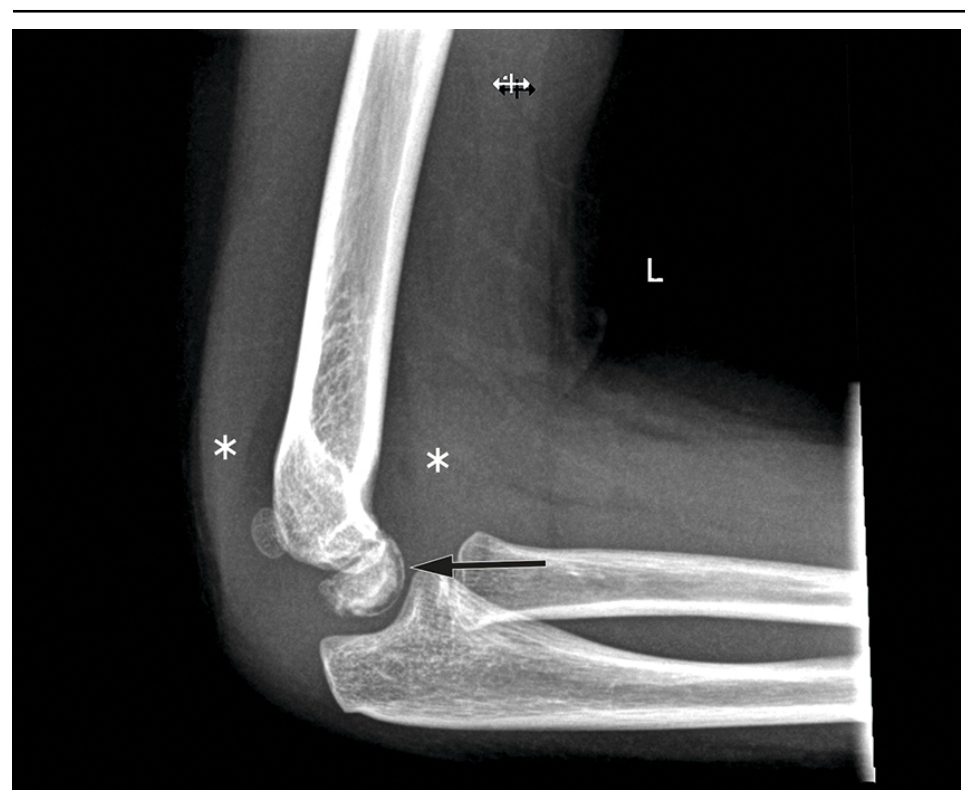

På røntgenbildet samsvarer oppklaringslinjen (markert med sort pil) med flere små gassbobler på samme sted på CT-bildet (hvit pil) - såkalt vakuumfenomen. Løftet fremre og bakre fettpute (markert med stjerner) er tegn på hydrops. Det er også litt ujevn benkontur ventralt i capitulum. Funn er typisk for Panners sykdom.

Røntgenbildet av venstre albue viser løftede fettputer som tegn på hydrops (markert med 
stjerner), men ingen synlig fraktur eller luksasjon. Det ses en tynn stripe med redusert bentetthet subkondralt i ventrale del av capitulum (sort pil), og på CT-bildet samsvarer linjen med flere små gassbobler på samme sted - såkalt vakuumfenomen. Det er også ujevn benkontur ventralt i capitulum. Funnene er typisk for Panners sykdom.

Bildene er av en jente i sen barnehagealder som kom til lege etter fire dagers sykehistorie med smerter og nedsatt bevegelighet i venstre albue uten kjent forutgående traume. Pasienten hadde hatt to episoder med subluksasjon av radiushodet, gjerne omtalt som pulled elbow, på samme side, sist for to år siden. Ved klinisk undersøkelse var hun lite smertepreget, men hadde $20-30^{\circ}$ redusert passiv og aktiv ekstensjon i albueleddet samt lett redusert supinasjon. For øvrig var det normale funn ved undersøkelse.

Panners sykdom er en osteokondrose av capitulums ossifikasjonssenter (1). Sykdommen ble først beskrevet i 1927 av den danske radiologen Hans Jessen Panner, som fant lignende radiologiske forandringer i capitulum hos en ung voksen som man tidligere hadde sett som osteokondrose i hofteepifysen (Calvé-Legg-Perthes' sykdom) (2). Tilstanden er sjelden og forekommer oftest hos gutter under ti år. Etiologien er ikke fullstendig kartlagt, men det er sett sammenheng mellom tilstanden og traume eller repetitiv valgusbelastning i albuen (3).

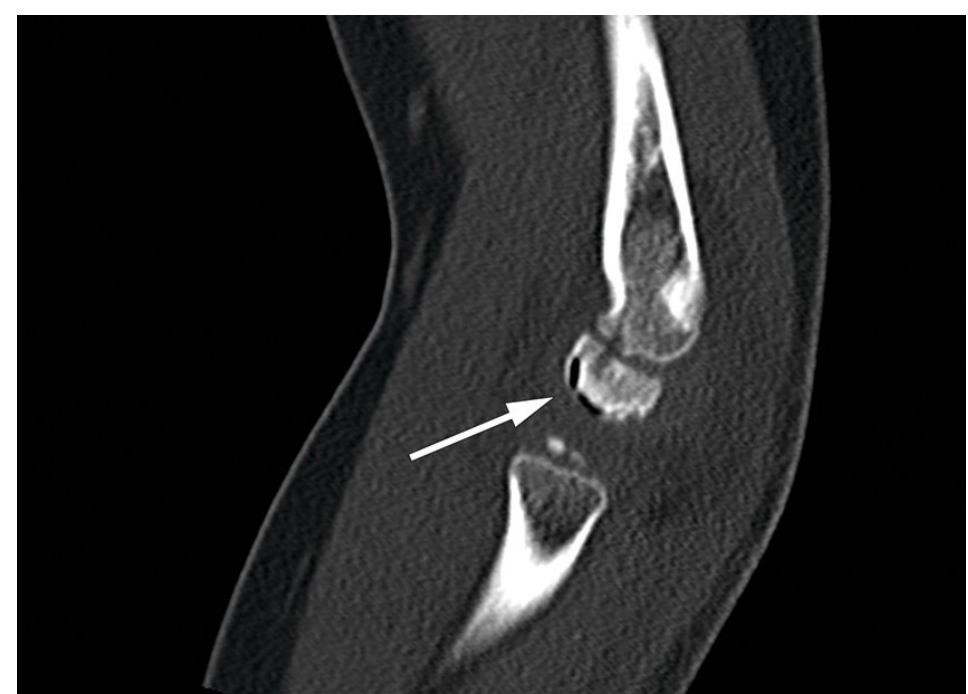

CT-bilde.Vakuumfenomen er markert med hvit pil.

Typiske kliniske funn ved Panners sykdom er smerte, hevelse, stivhet og innskrenket bevegelighet i albueleddet. Radiologisk kan man se morfologiske avvik, deform kontur, kollaps eller økt tetthet i capitulum (1). Subkondralt vakuumfenomen er et sjeldent funn, men er svært spesifikt for tilstanden. Vakuumfenomenet, som representerer subkondral gassdannelse, er et tegn på beniskemi og kan indikere aseptisk nekrose (1).

Den viktigste differensialdiagnosen til Panners sykdom er osteochondritis dissecans, som typisk forekommer hos eldre barn og ungdom i alderen 10-20 år. Det er uklart om Panners sykdom og osteochondritis dissecans er to forskjellige tilstander eller et kontinuum av samme tilstand. Osteochondritis dissecans er hyppigere assosiert med formasjon av intraartikulære løse benlegemer, lengre sykdomsforløp og hyppigere behov for kirurgisk intervensjon (3). Behandling av Panners sykdom er vanligvis konservativ med hvile og eventuelt immobilisering, og tilstanden tilheler vanligvis uten sekvele.

\section{LITTERATUR:}

1. Anisau A, Posadzy M, Vanhoenacker F. Panner's sisease: The vacuum phenomenon revisited. J Belg Soc Radiol 2018; 102: 67. [PubMed][CrossRef]

2. Claessen FMAP, Louwerens JKG, Doornberg JN et al. Panner's disease: literature review and treatment recommendations. J Child Orthop 2015; 9: 9-17. [PubMed][CrossRef]

3. Kobayashi K, Burton KJ, Rodner C et al. Lateral compression injuries in the pediatric elbow: Panner's disease and osteochondritis dissecans of the capitellum. J Am Acad Orthop Surg 2004; 12: 246-54. 
Publisert: 24. juni 2021. Tidsskr Nor Legeforen. DOI: 10.4045/tidsskr.21.0248 Mottatt 25.3.2021, første revisjon innsendt 11.5.2021, godkjent 19.5.2021.

() Tidsskrift for Den norske legeforening 2020. Lastet ned fra tidsskriftet.no 